\title{
ХРОМАТОГРАФИЧЕСКИЕ МЕТОДЫ СО СТАЦИОНАРНОЙ ГАЗОВОЙ ФАЗОЙ: ЖИДКОСТНО-ГАЗОВАЯ И ЖИДКОСТНО-ГАЗОАДСОРБЦИОННАЯ ХРОМАТОГРАФИЯ
}

\author{
Родинков О.В.
}

Институт химии Санкт-Петербургского государственного университета, Санкт-Петербург, Россия o.rodinkov@spbu.ru

DOI: 10.26902/ASFE-11_190

В докладе рассмотрены история возникновения, физико-химические закономерности, аналитические возможности и перспективы развития хроматографических методов со стационарной газовой фазой, основанных на проявлении капиллярных эффектов в гидрофобных микропористых средах: жидкостно-газовой и жидкостно-газоадсорбционной хроматографии. Показана более высокая эффективность обсуждаемых методов по сравнению с традиционными вариантами жидкостной хроматографии в процессах разделения и концентрирования летучих веществ [1].

Представление о хроматогафических процессах со стационарной газовой фазой, неизбежно присутствующей в микро- и мезопорах не смачиваемых подвижной жидкой фазой сорбентов за счет возникающего в них отрицательного капиллярного давления, позволило дать новое более адекватное объяснение механизма удерживания летучих веществ из водных растворов на гидрофобных сорбентах. Установлено, что в этом случае основной вклад в удерживание вносит адсорбция не из жидкой, а из стационарной газовой фазы, находящейся в наиболее тонких порах сорбента и обладающих максимальным адсорбционным потенциалом. При этом аналиты переходят из подвижной жидкой в стационарную газовую фазу и адсорбируются из этой фазы на поверхности сорбента.

На основе предложенной модели удерживания обоснованы принципы оптимизации процесса твердофазной экстракции и обращенно-фазовой высокоэффективной жидкостной хроматографии (ОФ ВЭЖХ). Нашли объяснение некоторые непонятные ранее явления: неоднозначное влияние температуры на параметры удерживания легко летучих веществ из водных и водно-органических растворов на гидрофобных сорбентах; аномально высокое удерживание из этих растворов алифатических углеводородов и постоянных газов; возможность улучшения сорбционного концентрирования в этих условиях за счет предварительной продувки сорбента потоком газа. Предложен новый методический подход к выбору состава водно-органического элюента в ОФ ВЭЖХ, учитывающий поверхностное натяжение органического компонента смешанных водно-органических элюентов. Показано, что при одинаковой элюирующей силе раствора применение органического компонента с более высоким поверхностным натяжением, приводящее к увеличению объема стационарной газовой фазы в колонке, позволяет повысить эффективность хроматографического процесса.

В качестве одного их перспективных направлений развития обсуждаемых методов представляется решение актуальной задачи современной ОФ ВЭЖХ - оптимизации влияния основных факторов разделения (температуры, давления и состава элюента) на величину ВЭТТ, исходя из объема стационарной газовой фазы в хроматографической колонке. Это направление находится в русле современной тенденции развития высокотемпературного варианта ВЭЖХ, особенного актуального в рамках концепции «зеленой химии». Другое направление связано с развитием поверхностно-слойных сорбентов. Далеко не полностью исчерпаны и аналитические возможности фронтального варианта жидкостно-газовой хроматографии как метода суммарного выделения газов, растворенных в воде, с их последующим газохроматографическим определением.

\section{Список литературы}

1. Москвин Л.Н., Родинков О.В. От жидкостно-газовой хроматографии к хроматомембранному массообменному процессу // Журнал аналитической химии. 2019. Т. 74. № 10. С. 729-751. 